\title{
Fast Neutron Irradiation Embrittlement- ductilitization of an Iron-based Amorphous Alloy using In Situ Synchrotron X-ray Diffraction
}

N Simos ${ }^{1 *}$, H Zhong ${ }^{2}$, Z Zhong ${ }^{1}$, F Camino', E Dooryhee ${ }^{1}$, S Ghose ${ }^{1}$, D Sprouster ${ }^{1,2}$, Z Kotsina ${ }^{3}$, I Şavklıyıldız ${ }^{4,5}$ and E Koray Akdoğan ${ }^{4}$

${ }^{1}$ Brookhaven National Laboratory, Upton, USA

2Stony Brook University, Stony Brook, USA

${ }^{3}$ National Center for Scientific Research - Demokritos Ag. Paraskevi, Greece

${ }^{4}$ Department of Materials Science and Engineering, Rutgers University, Piscataway, USA

${ }^{5}$ Faculty of Engineering, Department of Metallurgical and Materials Engineering, Selçuk University, Turkey

\begin{abstract}
Amorphous Fe-based nanostructured alloy coatings thermally sprayed on bcc steel substrate, were subjected to neutron irradiation doses up to $2 \times 10^{19} \mathrm{n} / \mathrm{cm}^{2}$. It is shown that the interplay between embrittlement and recovery of ductility is governed by amorphous to crystallization transition and phase decomposition in which temperature and irradiation dose have reciprocal effects. Microscopic (X-ray diffraction) observations on the behavior of the amorphous Fe-based alloy are correlated with relevant macroscopically observed mechanical behavior. It is shown that amorphous Fe-based alloy coatings maintain and even enhance their amorphous structure with irradiation, exhibit radiation-induced restoration of thermally-induced embrittlement and finally exhibit resistance to ductility loss up to the fluence of $2 \times 10^{18} \mathrm{n} / \mathrm{cm}^{2}$ and good thermal stability up to $350^{\circ} \mathrm{C}$. The latter is deduced from X-ray diffraction experiments of in-situ tensile strain application on the irradiated coating.
\end{abstract}

Keywords

Amorphous metals Crystallization, Amorphization, Thermal embrittlement, Neutron irradiation, Ductility restoration

\section{Introduction}

In recent years, amorphous metals in the form of nanostructured protective coatings on steel substrates have received substantial consideration for applications in extreme environments comprised of neutron fluxes, temperature and aggressive- ly corrosive environments. Such nanostructured coatings are postulated to exhibit superior resistance to radiation damage because the amorphous microstructure offers a plethora of sites to which radiation-induced defects can migrate where they are ultimately stopped. As a result, such nanostructured amorphous coatings may resist loss of

*Corresponding author: Nikolaos Simos, Brookhaven National Laboratory, Upton, NY 11973, USA, Tel: $+1-631-344-4790$

Accepted: April 30, 2020; Published: May 02, 2020

Copyright: (c) 2020 Simos N, et al. This is an open-access article distributed under the terms of the Creative Commons Attribution License, which permits unrestricted use, distribution, and reproduction in any medium, provided the original author and source are credited.

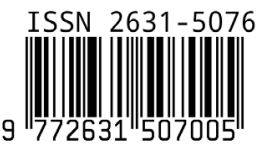

Simos et al. Int J Metall Met Phys 2020, 5:052 
ductility -a critical property for nuclear materials. Furthermore, amorphous metallic coatings are expected to exhibit very good oxidation and corrosion resistance in extreme environments of interest to nuclear applications thanks to their high content of alloying elements.

Studies by R. Gerling, et al. [1-3] reported on the thermal annealing of various amorphous metallic alloys such as $\mathrm{Fe}_{40} \mathrm{Ni}_{40} \mathrm{P}_{20}, \mathrm{Fe}_{40} \mathrm{Ni}_{40} \mathrm{~B}_{20^{\prime}} \mathrm{Cu}_{64} \mathrm{Ti}_{36^{\prime}}$ etc. wherein restoration of ductility using lowdose neutron irradiation was demonstrated. It was shown in [1-3] that amorphous alloys, whether already brittle in the as-quenched state such as $\mathrm{Fe}_{40} \mathrm{Ni}_{40} \mathrm{~B}_{20}$ or ductile in the as-quenched state but thermally embrittled afterwards, regained full ductility upon irradiation. This, what was reported in [1-3] proved that the embrittlement-crystallization process is indeed reversible at temperatures below the crystallization onset temperature. Neutron irradiation effects on amorphous and nanocrystalline alloys of $\mathrm{Fe}_{73.5} \mathrm{Cu}_{1} \mathrm{Nb}_{3} \mathrm{Si}_{13.5} \mathrm{~B}_{9}$ were studied [4] by exploring structural, magnetic, and mechanical properties following thermal embrittlement, and revealed the formation of excess free volume due to irradiation-induced swelling. High temperature $\mathrm{X}$-ray diffraction studies on as-quenched and thermally relaxed samples up to $400{ }^{\circ} \mathrm{C}$ showed the presence of singular broad diffuse maxima which is characteristic of an amorphous phase. It was also shown in [4] that crystalline $\alpha$-Fe (Si) Bragg reflections appeared in the spectrum upon annealing at $545^{\circ} \mathrm{C}$, which was followed by the formation of iron borides at $650{ }^{\circ} \mathrm{C}$. Moreover, in [4] it was reported that the fraction of amorphous phase increased at the expense of crystalline phases upon neutron irradiation. Such increase in amorphous phase content was attributed to partial re-amorphization in the nanocrystalline alloy, which was accompanied by restoration of ductility due to radiation-induced swelling. The amorphous and nanocrystalline $\mathrm{Fe}_{73}$. ${ }_{5} \mathrm{Cu}_{1} \mathrm{Nb}_{3} \mathrm{Si}_{3.5} \mathrm{~B}_{9}$ alloy was also studied by Mossbauer spectroscopy in [5], the results of which showed that formation of nanocrystals in the amorphous alloy can be triggered by annealing at $\sim 520{ }^{\circ} \mathrm{C}-\mathrm{a}$ temperature that is substantially lower than the Curie-Néel temperature of the as-quenched amorphous alloy $\left(T_{c}=602 \mathrm{~K}\right)$.

The effect of electron irradiation on the crystallization and phase stability of boron-containing amorphous alloys, Fe-Zr-B, was studied in $[6,7]$. As per what was reported in [6], under irradiation the amorphous phase of Fe-Zr-B system was not stable, which also caused accelerated crystallization. Reported also in [6] was the sensitivity of crystallization to the boron content of the alloy. In [8], irradiation effects in amorphous and crystalline sputter-deposited Mo-Ni coatings were investigated, where it was found that ion bombardment of crystalline Mo-Ni at temperature $<570{ }^{\circ} \mathrm{K}$ led to complete transformation into the amorphous state with irradiation at elevated temperatures accelerating thermally activated processes. In [9], neutron irradiation induced amorphous-to-crystalline phase transformation was studied in $\mathrm{Fe}_{83} \mathrm{~B}_{17}$ alloys, establishing radiation-induced changes in density, ductility, and Curie-Néel temperature. In [10], the thermal embrittlement in Fe-based amorphous ribbons was investigated, where it was discovered that Fe-based amorphous alloys become brittle after annealing to temperatures significantly lower than their crystallization temperatures. In [11], Fe-based amorphous composite coatings prepared by plasma re-melting were studied using DSC to confirm the presence of an amorphous phase. In that study ([11]), it was found that the coating had an exothermic peak crystallization over the 492.2 ${ }^{\circ} \mathrm{C} \sim 569.1{ }^{\circ} \mathrm{C}$ temperature range, and in the vicinity of $511.2{ }^{\circ} \mathrm{C}$ underwent an amorphous to crystalline phase transition that resulted in a diphasic composite in which the matrix is amorphous. At temperatures exceeding $569^{\circ} \mathrm{C}$ a structural phase transition in the crystalline phase was observed. In fact, X-ray diffraction patterns, which were obtained following plasma re-melting, revealed the presence of nanocrystalline phase in an amorphous matrix. In [12], Fe-based amorphous coatings were deposited on carbon steel by arc spraying and their microstructure was studied after re-melting. In [13], Fe-C-B ternary phase diagrams were calculated, which helped in evaluating potential applications of amorphous coatings as discussed in [14]. The first results on the 3D phase and strain mapping in such coating/substrate systems, which was determined by synchrotron energy dispersive X-ray ray diffraction using photon energies as high as 200 $\mathrm{keV}$, was reported in [15].

Macroscopic assessment of neutron irradiation effects on amorphous Fe-based coatings on alloy steels have been elaborated on in [16]. Even though some good stride were made toward harnessing the expected remarkable radiation and 
chemical (oxidation and corrosion) resistance of metallic amorphous nanostructured alloys in the form of protective coatings, application of such coatings on nuclear structural materials, i.e. nuclear steels, remains a challenge. Of primary interest is the functionality of the composite system (amorphous coating-steel substrate) and its collective response to stimuli consisting of irradiation fluxes and mechanical stress, all of which may co-exist in the working environment such as a nuclear reactor. In such applications, the ultimate goal is to extend the lifetime of structural component, which is made out of steel, by protecting it with an amorphous Fe-based alloy coatings. Protection of the steel by the amorphous coating can exist if and only if the coating resist embrittlement (loss of ductility) while providing chemical protection to the steel against oxidation and corrosion.

The motivation of this study is to provide a self-consistent experimental description of fast neutron irradiation on the phase evolution and mechanical properties of an iron-based amorphous alloy. To do so, advanced diffraction techniques by which space resolved, in situ probing of the material's microstructure became possible, were applied yielding insights as to the resistance against crystallization and embrittlement, albeit in an indirect way and through the interpretation of $\mathrm{x}$-ray diffraction data. Most relevant to the present study regarding multi-pass application via spraying of Fe-based amorphous coatings and their thermal characterization are presented in [17]. Specifically, thermal characterization of the as-sprayed Fe-based amorphous coatings prepared by high-velocity arc spraying was performed using DSC analysis and revealing the presence of primary crystallization as well as secondary crystallization, the latter stemming from residual amorphous phases [16].

Presented in the subsequent sections are: a) Characterization of the as received amorphous Febased coating and description of the experiments conducted (irradiation, X-ray diffraction and differential scanning calorimeter); $b$ ) Results of the energy dispersive $\mathrm{X}$-ray diffraction on radiation-induced amorphous-to-crystalline transitions, neutron-induced reversal of thermal embrittlement and ductility loss at higher fluences; c) X-ray diffraction assessment of amorphous coating evolution with neutron irradiation and in-situ strain; and finally d) A detailed assessment of irradiated Fe-based amorphous coatings in their substrate steel protective role.

\section{Experimental}

In what follows, we will give a description of the experimental methods used in this study. To keep the description concise, we will delineate the main aspect only and the details are referred to the references provided herein. Some results pertinent to the preliminary characterization of the material used in this study are included in this section.

\section{The amorphous Fe-based coating: Fabrication and preliminary characterization}

The synthesis of amorphous Fe coating on steel is based on a process called thermal spraying [17], which involved melting of an alloy feedstock in a plasma torch, spraying the molten metal through a nozzle, and rastering over the surface of the steel substrate that is kept at a significantly lower temperature. Typically, multiple passes are made to obtain the desired coating thickness. The molten metal is splat quenched on the steel surface, resulting in an amorphous solid [17]. Figure 1 depicts
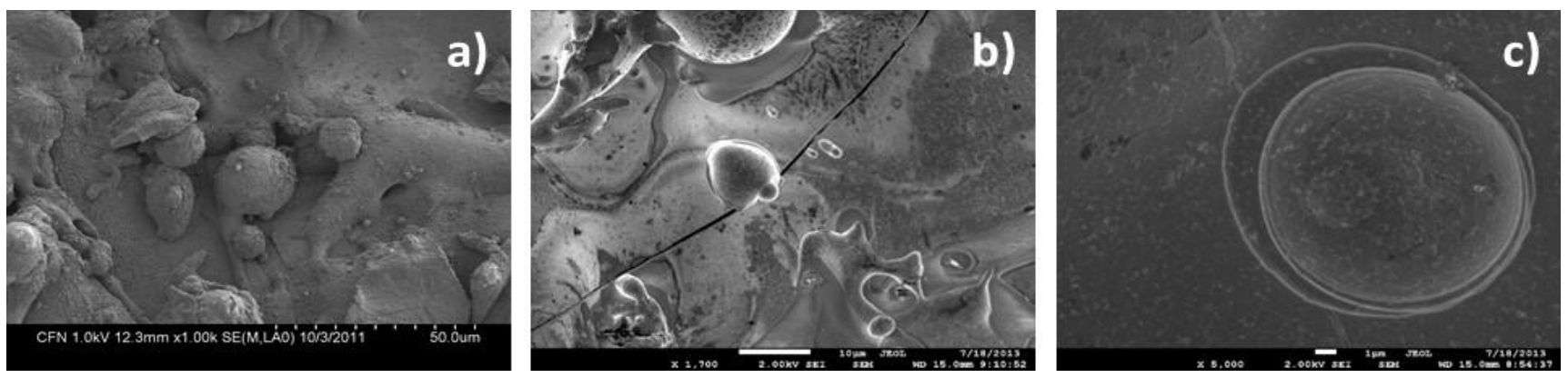

Figure 1: SEM micrographs (top surface) of as-received thermally sprayed amorphous Fe-based coatings on steel: a) Heterogeneous morphology showing droplets of supercooled amorphous phase due to nonuniform cooling during multi-pass deposition; b) Crack deflection due microscopic heterogeneity; c) Close-up of the microscopic heterogeneity. 
representative SEM micrographs the as-received Fe-based amorphous coatings of $240 \mu \mathrm{m}$ thickness that were deposited on $1.4 \mathrm{~mm}$-thick 4130 alloy steel. One observes a heterogeneous microstructure (see Figure 1a, Figure $1 \mathrm{~b}$ and Figure 1c) spanning from nanoscale to microscale in size that is the imprint of the thermal spray process, and the presence of pre-existing microcracks due to differential cooling between the rastered layers (see Figure 1b).

Figure 2 shows a representative energy dispersive spectroscopy (EDS) spectrum that identifies the elements in the coating as $\mathrm{Fe}, \mathrm{C}, \mathrm{B}, \mathrm{Mo}, \mathrm{W}, \mathrm{Cr}$, $\mathrm{Cu}$, and $\mathrm{Al}$. Here, the Fe-B-C ternary constitutes the base system with high temperature BCC-Fe forming the host, which is further alloyed with the other five alloying elements [18]. The presence of oxygen and carbon indicates that oxides and carbides have formed during deposition which takes place in air typically. One may observe the elevated levels of carbon that should be in the form of carbide phases in the coating. The present alloying elements expected to be partitioned in Fe-based phases depending on their solubility limit and according to their partial molar Gibbs free energy of mixing, e.g. $\mathrm{Fe}$ vs. ( $\mathrm{Fe} ; \mathrm{Cr} ; \mathrm{Mo})_{3} \mathrm{O}_{4}$. The variation of the elemental composition of the amorphous metallic coating was assessed by analyzing the EDS spectrum over several locations using standard methods and protocols. The average concentration of the elements was determined in atom percent as: B: $26.67 \%$, C: 26.19\%, O: 14.87\%, Al: 3.3\%, Si: 0.32\%, Cr: 5.01\%,
Fe: $16.03 \%$, Cu: $0.08 \%$, Y: $1.50 \%$, Mo: $5.94 \%, \mathrm{~W}$ : $0.08 \%$.

\section{Irradiation experiments}

A mixed field dominated by fast neutrons produced via spallation of energetic protons on targets was used as irradiating species. Specifically, the effects of three (3) irradiation experiments are reported in this article. Two of the said three experiments utilized the $118 \mathrm{MeV}$ protons at Brookhaven National Laboratory's BLIP facility: (i) Irradiation with spallation-produced fast neutrons to an integrated flux of $2 \times 10^{18} \mathrm{n} / \mathrm{cm}^{2}$ at $\sim 70{ }^{\circ} \mathrm{C}$ irradiation temperature and with the amorphous metallic phase and steel substrate in contact with de-ionized water, (ii) Irradiation with spallation generated fast neutrons to an integrated flux of $2 \times 10^{19} \mathrm{n} / \mathrm{cm}^{2}$ at $210{ }^{\circ} \mathrm{C}$ irradiation temperature under vacuum which aimed to assess the reversibility of the embrittlement-crystallization process at temperatures below the onset of crystallization. For both experiments the mean neutron energy was $12 \mathrm{MeV}$.

\section{X-ray diffraction experiments}

Post irradiation and thermal embrittlement assessments were carried out using the $200 \mathrm{keV}$ polychromatic X-rays of X17-B1 superconducting wiggler beamline at NSLS in the energy dispersive $X$-ray diffraction (EDXRD) mode [19]. The diffraction experiments operate in the Laue (a.k.a. transmission) geometry. The EDXRD method involves strongest penetrating $\mathrm{X}$-rays, enabling one to do $3 \mathrm{D}$

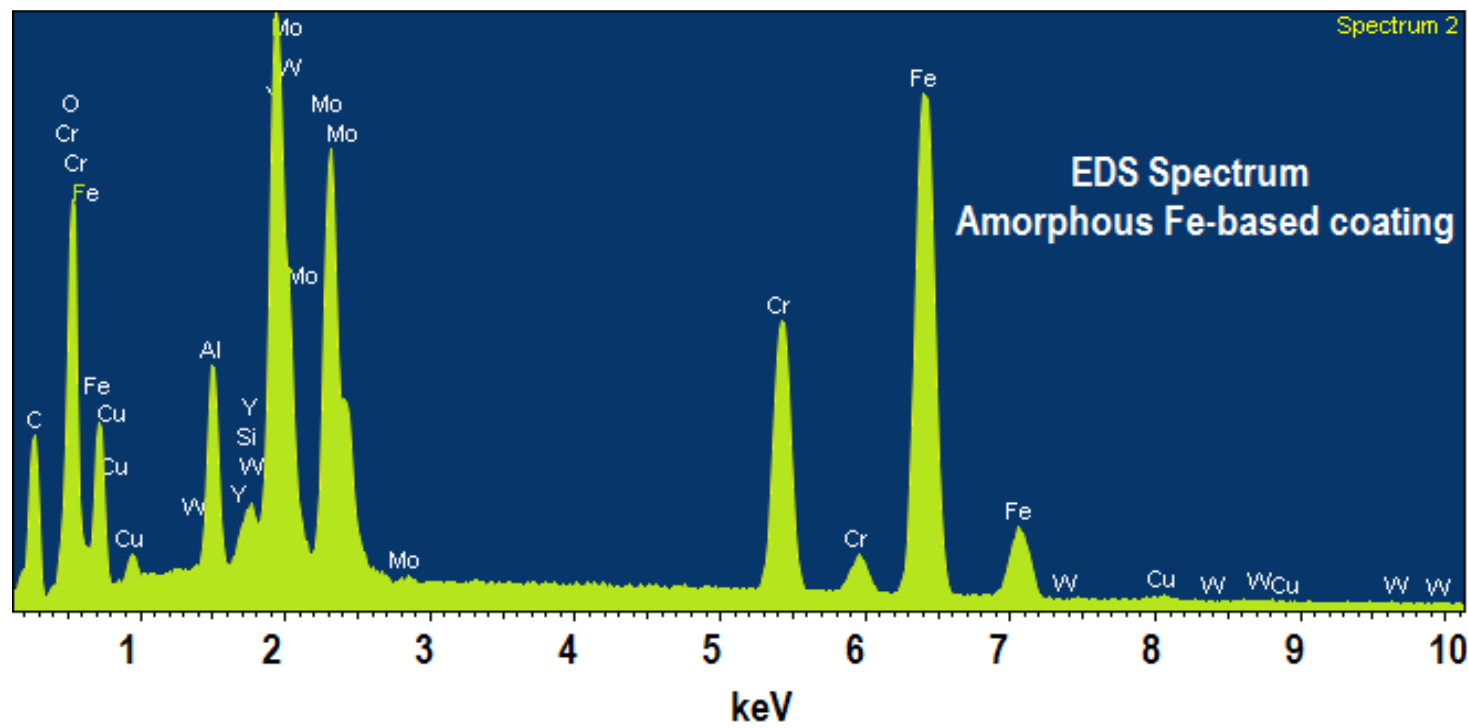

Figure 2: Energy dispersive spectroscopic analysis of the as-received amorphous Fe-based alloy coating. The identified elements are $\mathrm{Fe}, \mathrm{C}, \mathrm{B}, \mathrm{Mo}, \mathrm{W}, \mathrm{Cr}, \mathrm{Cu}$, and $\mathrm{Al}$. 

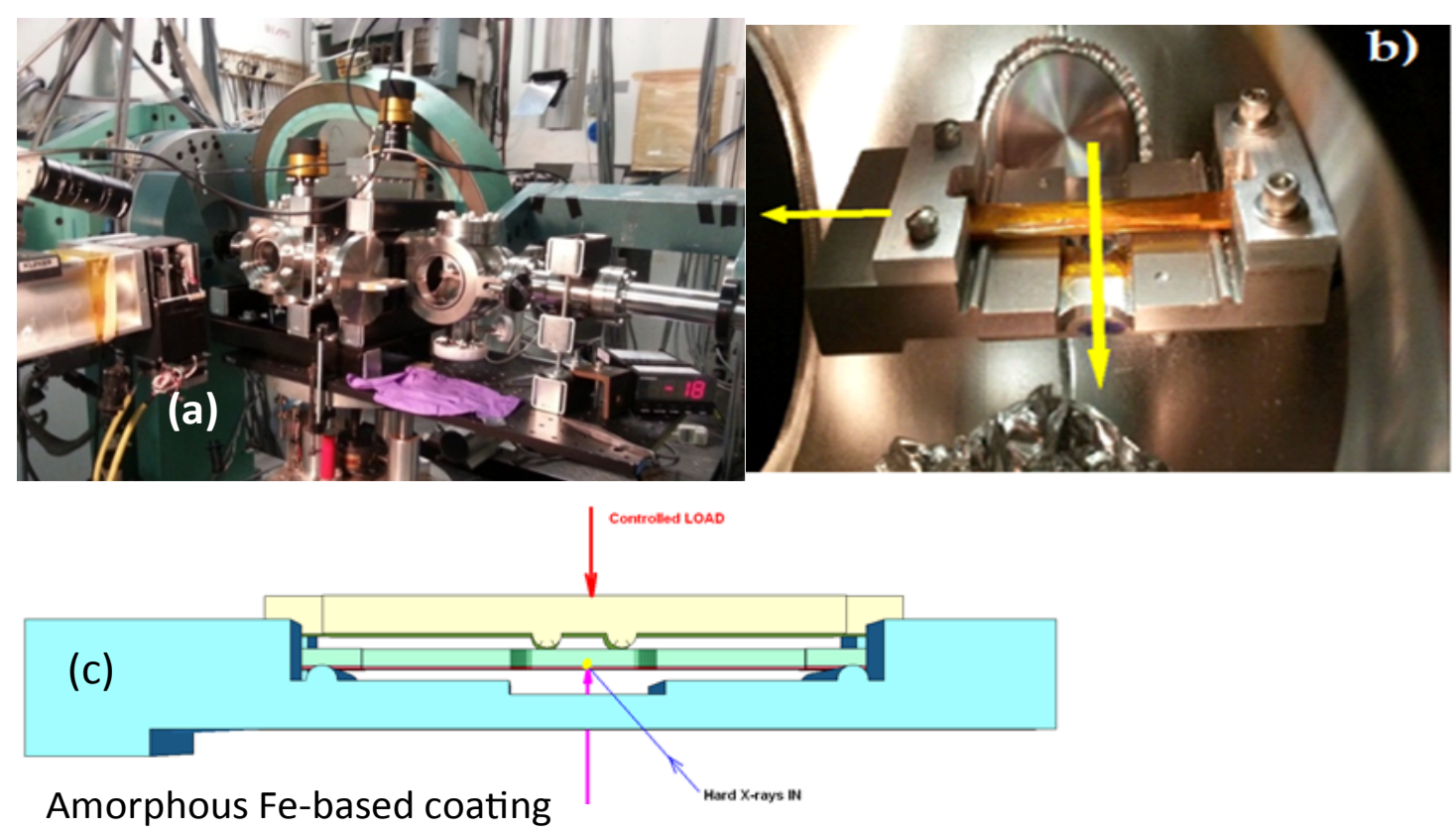

Figure 3: Experimental set-up: a) Overall view of the set-up showing at NSLS X17B1 beamline facilitating in-situ loading with EDXRD; b) Inside of the sample chamber depicting the orientation of the sample with respect to the incident beam. The Kapton-encapsulated irradiated amorphous Fe-based coating on steel specimen is inserted into the 4-point-bending mechanism; c) in-situ analyses of coated specimen schematic.

strain mapping with spatial resolution down to $\sim 5$ $\mu \mathrm{m}$ and a temporal resolution as low as 1 seconds (if needed). Both methods that were utilized in this study are not surface and/or subsurface limited as in the case of Bragg-Brentano diffraction methods [19]. The experimental set-up at the NSLS X17B1 beamline is shown in Figure $3 a$, along with the details of the encapsulated samples that were mounted on an in-house, custom-made stage (see Figure $3 b)$, which was custom built. In-situ stress states at two loading levels (designated as $P_{1}=55.1 \mathrm{~kg}$ (25 lbs.) and $P_{2}=110.2 \mathrm{~kg}$ (50 lbs.), where $P_{2}$ is the maximum load the experimental stage can deliver. Such loads were imposed on unirradiated and irradiated samples in the 4-point-bending (4PB) geometry as depicted in Figure 4 a by using an in-house, custom-made system.

The orientation of the specimens used in such studies is shown in Figure 4b. The mechanical response of the coating was measured in tension, with the diffraction volume placed in the body center, and using $\mathrm{x}$-rays in the transmission mode, thereby making the measurement insensitive of the surface phenomena. The macroscopic stress state and deformation of the amorphous Fe-based coating on 4130 steel were obtained using a high-fidelity $3 \mathrm{D}$ numerical analysis based on nonlinear finite element techniques. The objective of such analysis was to obtain a representative profile of the stress across the thickness of the composite structure, and in particular, the effect of the amorphous coating in altering the ideal 4-point-bending state of stress. A closer look at Figure $4 a$ is the emulation of the X-ray diffraction with in situ stress and deformation, and in Figure $4 \mathrm{~b}$ is the predicted stress profile under maximum load. Here, the total length of the sample is $42 \mathrm{~mm}$, the gauge length (central section) is $6 \mathrm{~mm}$ long, and the width is $1.5 \mathrm{~mm}$, giving a total thickness of $1.4 \mathrm{~mm}$ (steel substrate) + $240 \mu \mathrm{m}$ (amorphous Fe-based coating). The simulations were used as a guide in the ensuing in situ $X$-ray analysis of $d$-spacing shifts from which strains were assessed, and the stresses were computes (see [20]).

The response of the amorphous Fe-based alloy coating to irradiation were assessed in post-irradiation analyses under extreme stress via X-ray diffraction using $67 \mathrm{keV}$ monochromatic $X$-rays at the XPD beamline of NSLS II, and $200 \mathrm{keV}$ polychromatic $\mathrm{X}$-rays at the X17-B1 beamline of NSLS. The system set-up utilized for the studies at XPD was identical to the one depicted in Figure 3 and Figure 4, while a detailed description of the diffraction geometry and pertinent details about the system used at 

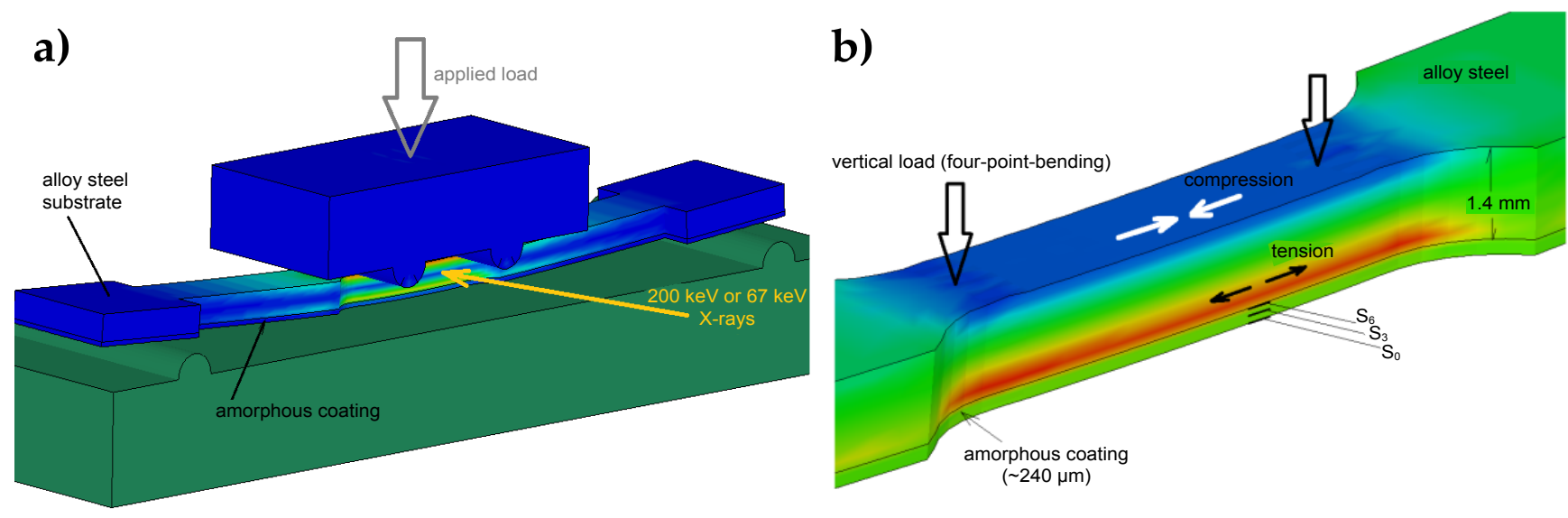

Figure 4: a) Simulation of the in-situ stress state generated in the amorphous Fe-based alloy coating-steel substrate composite system using finite element analysis under 4-point bending; and b) The stress-state generated under load with amorphous coating under tension. The simulations were used as a guide in the ensuing in situ $\mathrm{X}$-ray analysis of $\mathrm{d}$-spacing shifts.
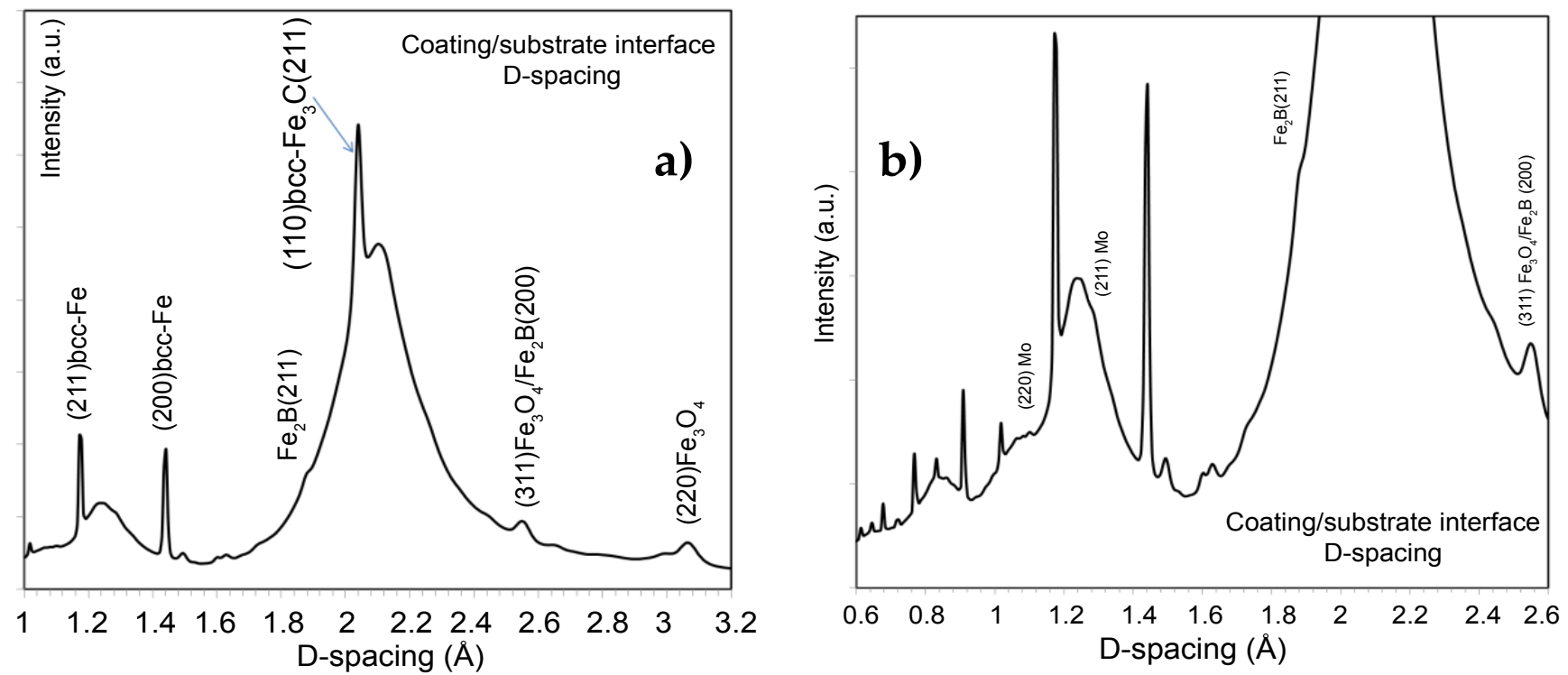

Figure 5: Representative X-ray spectrum (XRD, $67 \mathrm{keV} \mathrm{X-rays)} \mathrm{of} \mathrm{the} \mathrm{amorphous} \mathrm{Fe-based} \mathrm{alloy} \mathrm{coating} \mathrm{and} \mathrm{steel}$ substrate composite system: a) The spectrum of the coating; and b) The spectrum of the interfacial region between the coating and steel substrate.

X17-B1 can be found elsewhere $[19,20]$. As preliminary characterization to establish the baseline for the as-received amorphous Fe-based coatings, $X$-ray diffraction patterns were used in conjunction with the EDS spectra, to identify the phases present in the unirradiated and thermally untreated specimens. Figure 5 depicts diffraction patterns and qualitative phase analyses in the amorphous Fe-based alloy coating (see Figure 5a), and that in the interface with the BCC-steel substrate, which includes the presence of alloying elements.

The X-ray spectrum of the amorphous Fe-based alloy prior to thermal spraying (not shown) ([21]) consists of a single ultra-broad peak spanning 6.711 degrees 2-theta, the peak apex of which coincides with the (110) peak positions of BCC-Fe (high temperature allotrope) at $1663{ }^{\circ} \mathrm{C}$ (Powder Diffraction File PDF\#97-004-3452). Such an ultra-broad peak corresponds to a crystallite size of $1.6 \mathrm{~nm}$ (coherently diffracting domain size representing translation symmetry), which essentially means that there is no long range translation order in the material, i.e. the solid amorphous [15]. However, based on analysis of the EDS spectra and X-ray diffraction patterns of the amorphous coating, it is assessed that the thermal sprayed amor- 
phous Fe-based coating under study is essentially a 4-phase composite system consisting of (i) BCC $\mathrm{Fe}: \mathrm{Cr}, \mathrm{Mo}$;W (metallic; crystalline solid solution), (ii) ( $\mathrm{Fe}, \mathrm{Cr}, \mathrm{Mo})_{3} \mathrm{O}_{4}$ (ceramic; crystalline solid solution), (iii) ( $\mathrm{Fe}, \mathrm{Cr})_{2} \mathrm{~B}$ (ceramic boride; crystalline solid solution) and (iv), amorphous Fe:B, Cr;Mo;W (metallic; amorphous solid solution; very broad peak around ä-Fe (110). Phase separation, crystallization, as well as oxidation are evident in the coating. Formation of oxide phases $\left(\mathrm{Fe}_{3} \mathrm{O}_{4}\right.$-based) and borides ( $\mathrm{Fe}_{2} \mathrm{~B}$ based) may contribute to the embrittlement of the coating. The major peak observed in the spectrum, which appertains to the room temperature stabi- lized BCC ä-Fe (see Figure 5), becomes narrower in the as-deposited coating (see Figure $5 a$ ), but still is very broad (corresponding to 2 degrees in 2-theta). This indicates that the thermal history of the coating allowed for an increase in the coherence length of the material, indicating tendency toward crystallization. However, such a broad peak still indicates poor crystallinity, i.e. amorphous state. Essentially, the coating is an amorphous metal matrix composite. Here, the matrix is a ductile phase, while the reinforced phases are either ductile metals or hard carbides or borides. As can be verified from Figure $5 b$, the coating mostly retains its phase composi-
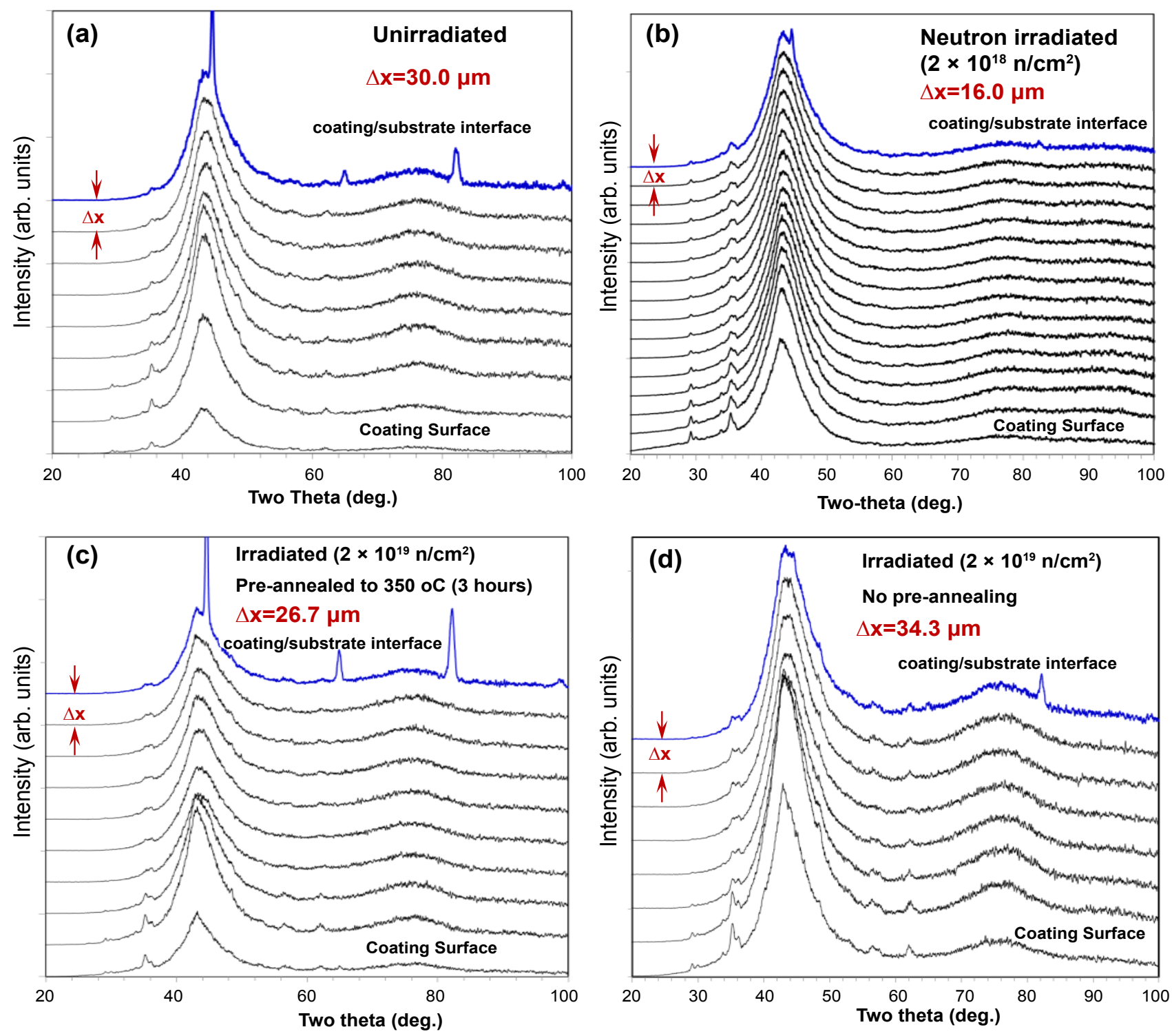

Figure 6: EDXRD diffraction patterns (transmission mode) over the $240 \mu \mathrm{m}$-thick amorphous Fe-based metallic coating for four states: a) Unirradiated; b) Irradiated to $2 \times 10^{18} \mathrm{n} / \mathrm{cm}^{2}$ in water $70{ }^{\circ} \mathrm{C}$, (c) irradiated to $2 \times 10^{19} \mathrm{n} /$ $\mathrm{cm}^{2}$ in vacuum following thermal embrittlement to $350^{\circ} \mathrm{C}$ and (d) irradiated to $2 \times 10^{19} \mathrm{n} / \mathrm{cm}^{2}$ in vacuum with no pre-irradiation thermal treatment, showing the effects of temperature and irradiation. (For sample geometry, see Figure 4). 
tion at the coating-substrate interface. However, one observes molybdenum (Mo) reflections that originate from the substrate in which $\mathrm{Mo}$ is an alloying element. Since individual Mo peaks are detected at the interface, one arrives at the conclusion that some segregation of Mo took place, and that Mo exists at the interface either in elemental form or as an alloy of unknown composition.

\section{Results and Discussion}

In this section the results of (a) Radiation-induced amorphous-to-crystalline transitions; (b) Neutron-induced reversal of thermal embrittlement; and (c) Ductility loss above a threshold fluence in Fe-based amorphous alloy coating are presented in detail.

\section{Radiation-induced amorphous-to-crystalline transitions}

Figure 6 depicts the diffraction patterns across the $240 \mu \mathrm{m}$ thick amorphous Fe-based metallic coating for various irradiation conditions and thermal treatment temperatures. As discussed before (see appertaining discussion for Figure 5), the pristine Fe-based alloy coating exhibits a very broad maximum in diffracted peak intensity representing in amorphous matrix on which some sharp Bragg peaks of crystalline secondary phases are superimposed (see Figure 6a). When the coating is ir- radiated to $2 \times 10^{18} \mathrm{n} / \mathrm{cm}^{2}$ at $70{ }^{\circ} \mathrm{C}$ in water (see Figure $6 \mathrm{~b}$ ), one observes that the crystalline secondary phases vanish throughout the coating as well as the interface. Here, the temperature is not high enough have an impact on the structure of the coating because one well below the melting temperature of the species involved, resulting in very small diffusivities. As such, $2 \times 10^{18} \mathrm{n} / \mathrm{cm}^{2}$ fluence is sufficient to perturb the crystalline order of the secondary phase and dissolve the species in the amorphous Fe-based alloy matrix as can be inferred by comparing Figure $6 \mathrm{a}$ and Figure 6b. However, one observes the re-appearance of the sharp Bragg reflections of the secondary phases and also narrowing of the amorphous intensity maximum when the coating is first subjected to a thermal treatment at $350^{\circ} \mathrm{C}$ (a.k.a. thermal embrittlement), and then followed by irradiation to $2 \times 10^{19} \mathrm{n} / \mathrm{cm}^{2}$ at $210^{\circ} \mathrm{C}$ (see Figure $6 \mathrm{c}$ ). Under these conditions, it is clear that the thermal treatment induces crystallization of secondary phases as well as an increase in crystallinity of the amorphous matrix as its intensity maximum becomes narrower. However, the effect of irradiation is completely absent because of the heat treatment at $350{ }^{\circ} \mathrm{C}$, indicating high atomic caused crystallization (see Figure 6c). This conclusion is further substantiated considering the fact that coatings that were irradiated with a fluence of $2 \times 10^{19} \mathrm{n} / \mathrm{cm}^{2}$ at $210{ }^{\circ} \mathrm{C}$ without any pre-anneal-

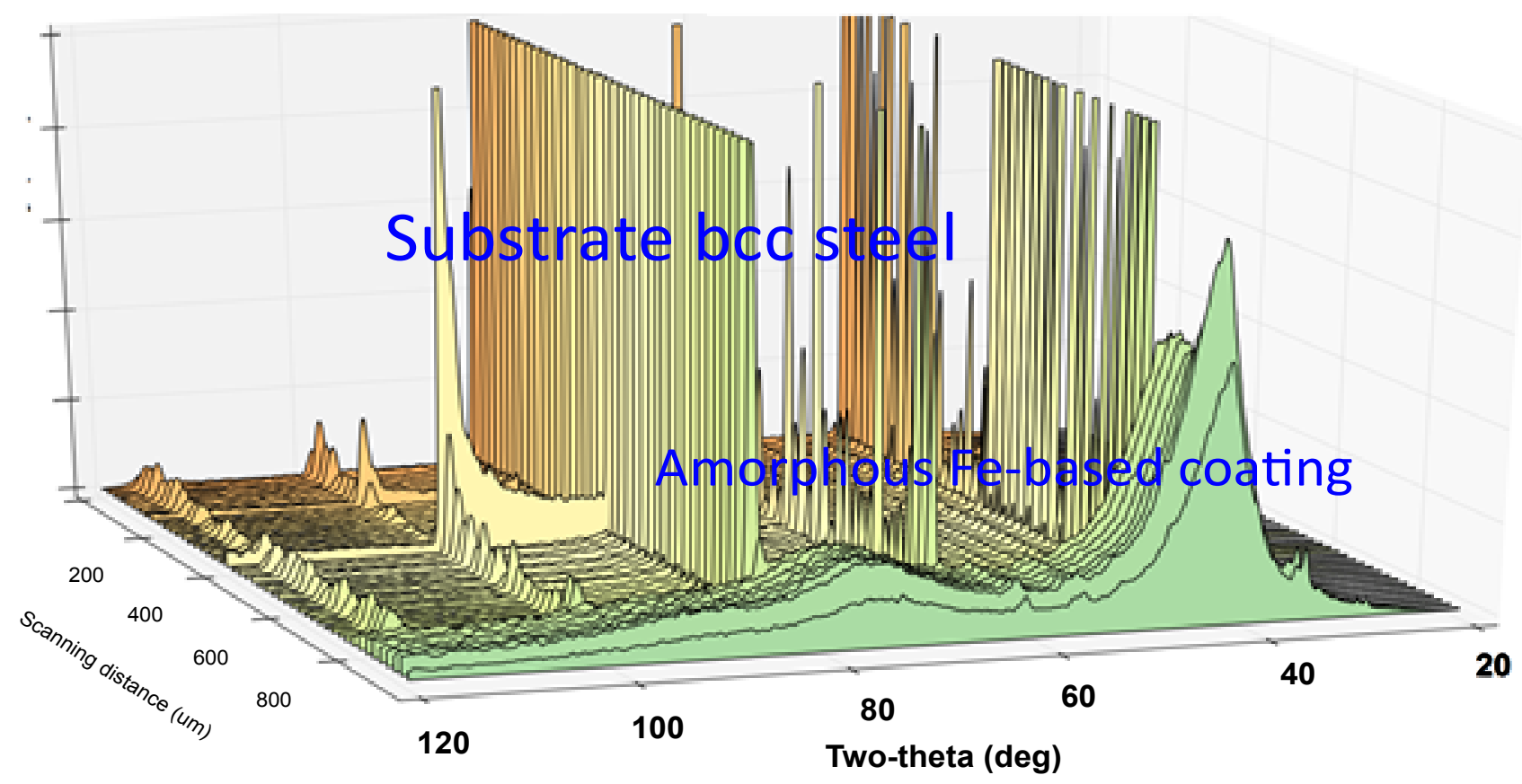

Figure 7: EDXRD diffraction patterns (transmission mode) across the $240 \mu$ m-thick amorphous Fe-based coating and substrate steel following irradiation to $2 \times 10^{19} \mathrm{n} / \mathrm{cm}^{2}$. 
ing at $350{ }^{\circ} \mathrm{C}$ do not exhibit crystallization, i.e. no Bragg peaks re-appear, and intensity maximum of the amorphous coating remains broad. It should be noted that the matrix of the coating remains amorphous for the conditions reported herein. In other words, the data in had clearly shows the opposing effect of temperature, which favors crystallization, and irradiation, which favors the amorphous state by breaking down the translational symmetry of the crystalline state $[6,7]$.

While both EDXRD and powder diffraction studies confirmed that the Fe-based alloy coating remained amorphous up to a fluence of $2 \times 10^{19} \mathrm{n} /$ $\mathrm{cm}^{2}$, it is not possible to deduce whether the amorphous structure remained ductile or underwent embrittlement from measurements thus far (Figure 7).

\section{Neutron-induced reversal of thermal embrit- tlement}

To study the effect of thermal aging on the amorphous Fe-based alloy coating, which contains $26.67 \%$ boron (see Figure 2), and the subsequent effects of neutron irradiation, specimens were firstly annealed at $350{ }^{\circ} \mathrm{C}$ in vacuum for 3 hours. These thermally treated samples along with untreated ones were then irradiated under vacuum to a dose of $\sim 2 \times 10^{19} \mathrm{n} / \mathrm{cm}^{2}$. Figure 8 a depicts a representative SEM micrograph of the amorphous Fe-based coating that was subjected to thermal embrittlement at $350{ }^{\circ} \mathrm{C}$, revealing the onset of crystallization by the formation of nanoscale precipitates of 100-200 nm size. To confirm the SEM observation, thermal analyses using DSC were conducted on amorphous Fe-based alloy coatings. As seen in Figure 8b, one observed two discontinuities over the range $340-350{ }^{\circ} \mathrm{C}$, which confirmed that some degree of crystallization is taking place in the amorphous alloy. We attribute the observed embrittlement to the internal elastic strains that are induced by molar volume changes associated with the decomposition products, and the elastic moduli contrast between the matrix and the precipitates [22]. The results reported herein are in agreement with observations reported in [1], where thermal embrittlement in the $320-340{ }^{\circ} \mathrm{C}$ range was attributed to partial phase decomposition in amorphous matrix formed by $\mathrm{Fe}_{40} \mathrm{Ni}_{40} \mathrm{~B}_{20}$ alloy.

Several studies on amorphous $\mathrm{Fe}_{40} \mathrm{Ni}_{40} \mathrm{~B}_{20}$ and $\mathrm{Fe}_{73.5} \mathrm{Cu}_{1} \mathrm{Nb}_{3} \mathrm{Si}_{13.5} \mathrm{~B}_{9}$ ribbons $[1,2,4]$, focusing on the restoration of ductility following thermal embrittlement by neutron irradiation made observations regarding thermal aging at temperatures below the crystallization temperature. In such materials, a tendency toward embrittlement is observed even in the amorphous state. The opposing embrittlement-ductilitization processes in such amorphous alloys were found to be a reversible below the onset of crystallization. It was found that annealing at low temperatures caused embrittlement in the $320-340{ }^{\circ} \mathrm{C}$ range due to precipitate formation inside of the amorphous alloy matrix. Furthermore,
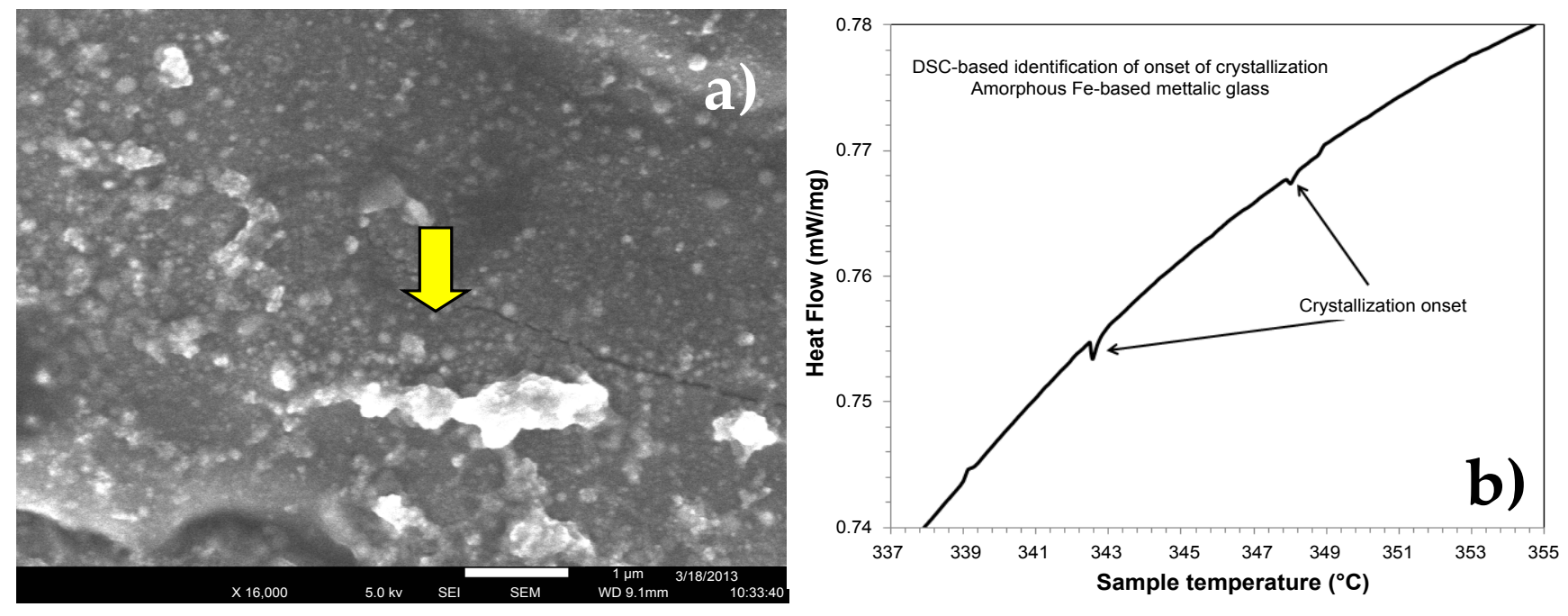

Figure 8: Thermal aging of amorphous Fe-based alloy coating at $350^{\circ} \mathrm{C}$ : a) Showing nanoscale crystallization of precipitate phases and embrittlement (yellow arrow); and b) Confirmation using differential scanning calorimetry of the initiation of crystallization by precipitate formation far below the glass transition temperature of the amorphous material (coating). 
radiation-induced excess volume (swelling) that was generated because of subsequent neutron irradiation to fluence up to $\sim 10^{19} \mathrm{n} / \mathrm{cm}^{2}$ (fluence similar to what was used in this study) recovered the loss in excess free volume, restoring the ductility thereby. Moreover, the presence of boron, in particular the ${ }^{10} \mathrm{~B}$ isotope with the large capture section of thermal neutrons, is known to have an impact on the observed phenomena. That is so since high energy $\alpha$ - and Li-particles, which result from the said capture, induce extra damage in addition to the one caused by fast neutrons. As such, it is imperative to assess radiation-induced restoration of ductility in the thermally embrittled amorphous Fe-based alloy coatings using fast neutrons, which we will address next, and then elaborate on the results by seek correlations with reminiscent material system reported in the literature (see [1-4]).

Post-irradiation X-ray diffraction studies across $240 \mu \mathrm{m}$ thick amorphous Fe-based alloy coatings on steel substrate was performed to probe the processes accompanying thermal embrittlement and subsequent irradiation. It should be noted that in previous report on the subject use amorphous Febased alloys in the form of free-standing ribbons, which should be considered as a limit boundary conditions. In our case, the amorphous Fe-based alloy coatings in a pseudo plane stress condition, and thus, mimic the conditions encountered in engineering applications of such materials.

Shown in Figure 9a are representative X-ray diffraction patterns of an unirradiated amorphous Fe-based alloy coating at several scanning depths (indicated as S51-S54) within the $240 \mu \mathrm{m}$ coating layer for both the as-is and the thermally embrittled ones at $350{ }^{\circ} \mathrm{C}$. For the non-embrittled case, the intensity of the diffraction peak characterizing the amorphous structure is invariant at the scanning depths. On the contrary, following annealing at $350^{\circ} \mathrm{C}$, one observes significant intensity reduction that varies with depth within the coating. This is attributed to the method by which the amorphous coating was formed on the steel substrate by the so-called thermal spraying deposition process, which involves multiple passes to build the desired coating thickness. The layer-by-layer formation of the coating inevitably results in compositional variations, differential cooling and position-dependent phase separation, and consequently thermal embrittlement variation. We infer that the thermal treatment amplifies the compositional variations in the deposition layers of the coating, resulting in a variation in scattered intensity in the intensity maximum of the amorphous phase.

Untreated and thermally embrittled were then irradiated to a fluence of $2 \times 10^{19} \mathrm{n} / \mathrm{cm}^{2}$, and then the diffraction patterns were obtained under identical conditions as for unirradiated samples. As seen in Figure 9b, one observes an increase in intensity and no spatial variation as in the case for unirradiated specimens. Hence, we conclude that irradiation has reversed the effects induced by thermal embrittlement. This important finding is in agreement with observation made in previous studies [1-4] that reported the recovery of the fracture strain of irradiated ribbons of amorphous Fe-based alloys under bending. Here, the thermally induced
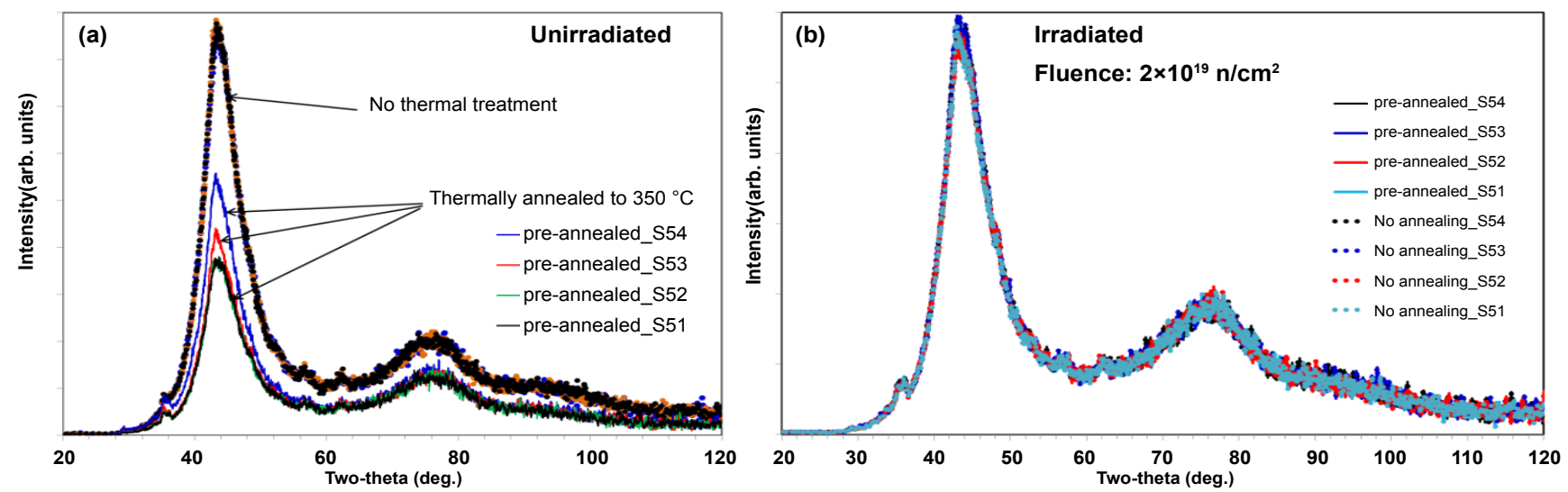

Figure 9: Spatially-resolved X-ray diffraction patterns (EDXRD) of: a) Unirradiated and thermally embrittled amorphous Fe-based alloy coating due to thermal annealing at $350{ }^{\circ} \mathrm{C}$; and b) Irradiated amorphous Fe-based alloy coating showing radiation-induced reversal of embrittlement that was due to thermal annealing at $350{ }^{\circ} \mathrm{C}$ prior to neutron irradiation. 

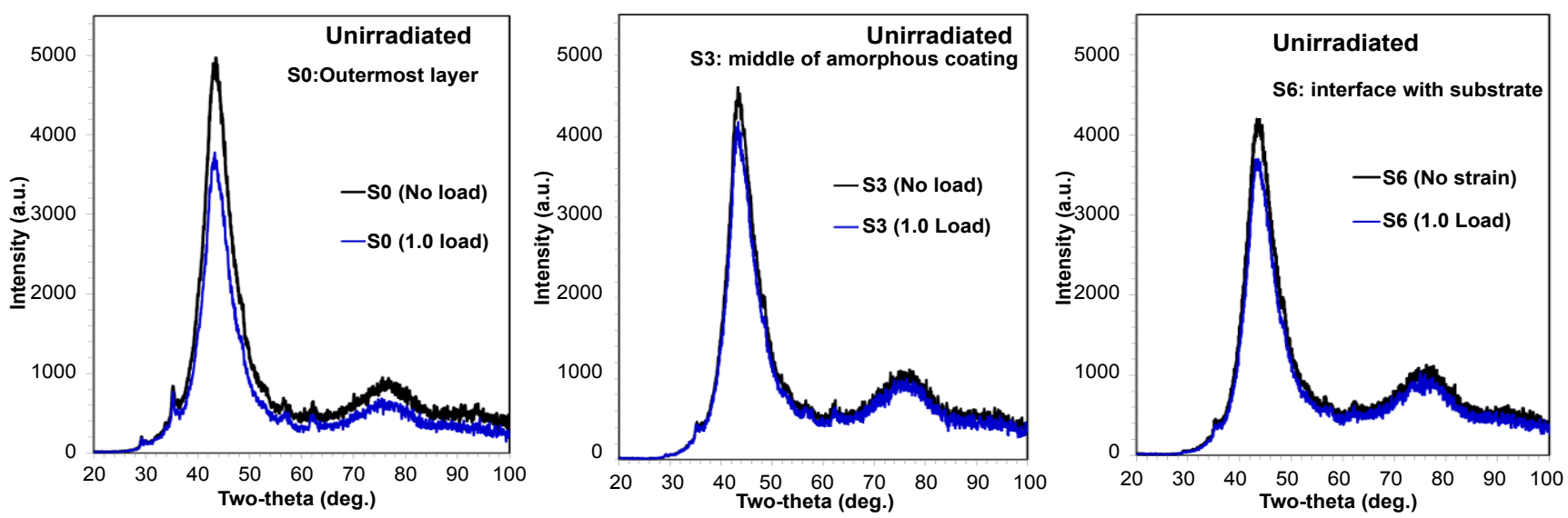

Figure 10: X-ray diffraction patterns (EDXRD) of unirradiated amorphous Fe-based alloy coating showing: a) Subsurface of coating; b) Center of coating; and c) Coating-substrate interface under tension in four point bending. (For sample geometry see Figure 4).

embrittlement is attributed to the loss of excess free volume that was retained during quenching from high temperatures. The said excess volume is expected to vary over the thickness of the coating due to the multiple spraying passes ones uses in thermal spraying of the coating. On the contrary, the subsequent restoration is caused by radiation-induced excess volume generation or swelling. The said radiation-induced swelling due to defect generation would lead to a decrease in overall density, which will increase in direct proportion to radiation dose. This is also evident in Figure 7c, where intensity reduction in the characteristic amorphous peak is observed.

\section{Microstructural assessment of irradiated amor- phous Fe-based alloy coatings under load}

The microstructural response of the amorphous Fe-based coating under tensile stress in both unirradiated and irradiated states was studied with in-situ EDXRD diffraction using polychromatic 200 keV X-rays and in situ diffraction using monochromatic $67 \mathrm{keV}$ powder diffraction techniques (see Figure 3 and Figure 4). Here, we observed the variation in the intensity and shape of the broad peak appertaining to the amorphous Fe-based phase so as to monitor the evolution of ductility in the amorphous coating with increasing neutron irradiation fluence.

Typical specimens consisted of a $240 \mu \mathrm{m}$ thick amorphous Fe-based alloy coating on a $1.4 \mathrm{~mm}$ thick steel substrate, which kept the coating tensile in plane stress in the $4 \mathrm{~PB}$ configuration (see Figure $4 b)$. Measurements were made at 3 locations in the sample so as to profile the variation in properties (near the surface is designated as S0, the middle of the coating as S3, and near the surface as S6). The peak load applied by the experimental stage was of the order of $50 \mathrm{lbs}$. and is designated as 1.0 Load. Figure 10 presents the evolution of diffraction patterns at the three selected locations under maximum (1.0 Load $=22.7 \mathrm{~kg}$ ). The highest intensity reduction was observed at the coating surface, which is the region carrying the maximum tensile load (see Figure 10a). Minimal reduction in intensity was observed in the mid-depth of the coating (see Figure 10b), which is where microcracking is expected. That is so because the internal strains arising from differential cooling and the applied tensile stress superimpose. Such microcracking reduces the effective density of the coating, resulting in reduced diffracted intensity. Even higher stresses are expected at the location near the coating-substrate interface (see Figure 10c), which is due to the elastic moduli mismatch between coating and substrate.

Following neutron irradiation to $2 \times 10^{18} \mathrm{~cm}^{-2}$ at a low temperature $\left(70^{\circ} \mathrm{C}\right)$ the response under load for two load levels (1/2 and 1.0 Load; 1.0 Load = $22.7 \mathrm{~kg}$ ) was measured. As seen in Figure 11, it is evident that the diffraction intensity reduction is absent within experimental scatter, indicating that the amorphous Fe-based coating has not only retained its ductility that was acquired during thermal spraying, but also has experienced enhancement due to neutron irradiation as compared to the results of Figure 10. The observed recovery in peak intensity is attributed to the swelling or radi- 

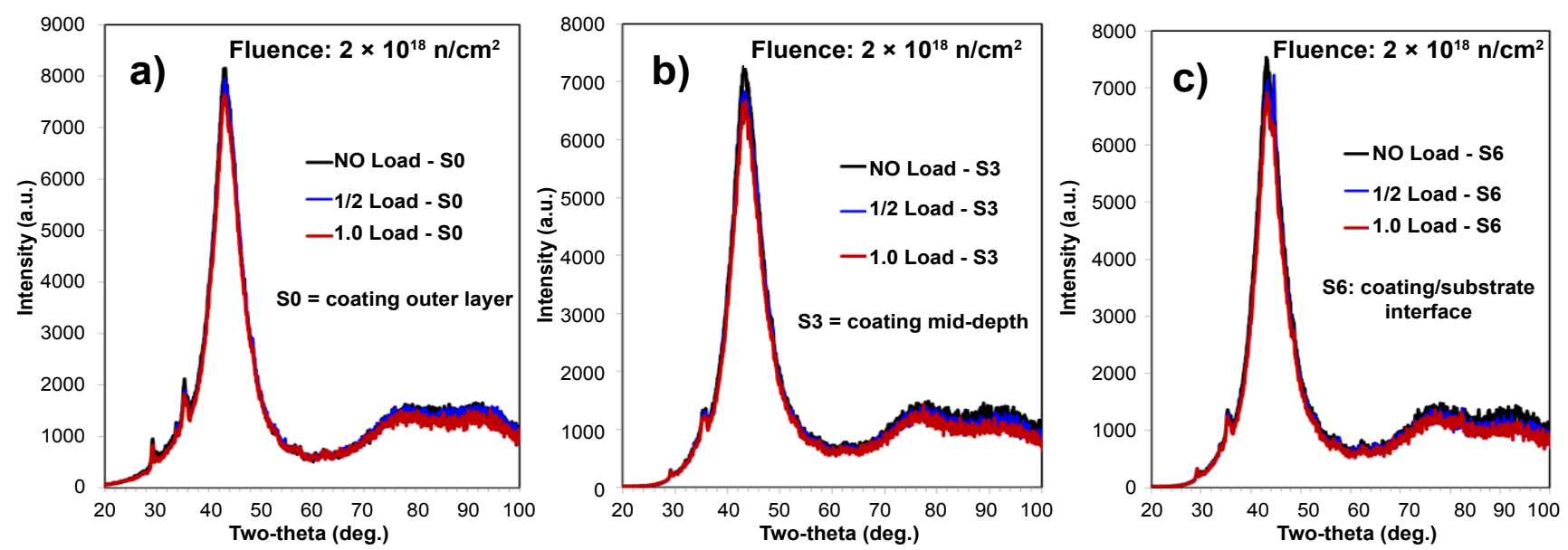

Figure 11: X-ray diffraction patterns (EDXRD) of irradiated amorphous Fe-based alloy coating showing: a) Subsurface of coating; b) Center of coating; and c) Coating-substrate interface under tension in four point bending after irradiation to $2 \times 10^{18} \mathrm{n} / \mathrm{cm}^{2}$ at $70^{\circ} \mathrm{C}$. (For sample geometry see Figure 4).
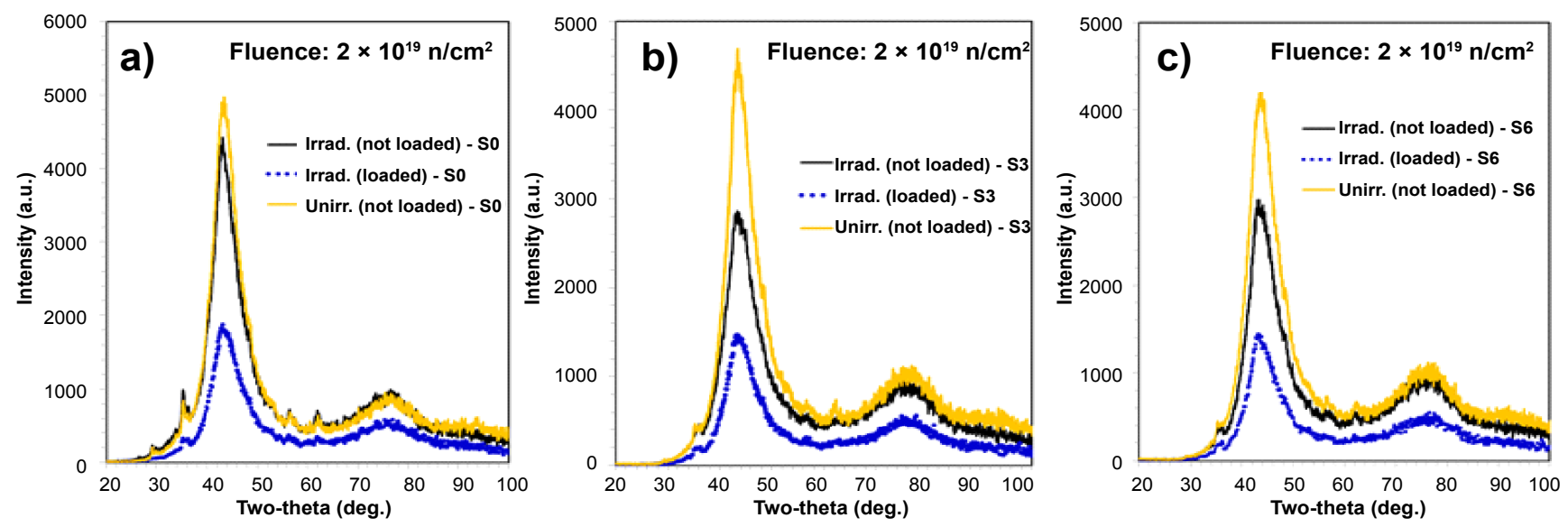

Figure 12: X-ray diffraction patterns (EDXRD) of irradiated amorphous Fe-based alloy coating showing: a) Subsurface of coating; b) Center of coating; and c) Coating-substrate interface under tension in four point bending after irradiation to $2 \times 10^{19} \mathrm{n} / \mathrm{cm}^{2}$ at $210^{\circ} \mathrm{C}$.

ation-induced excess volume discussed previously.

However, irradiation at higher temperature $\left(210^{\circ} \mathrm{C}\right)$ that is also accompanied with a ten-fold increase in fluence to $2 \times 10^{19} \mathrm{n} / \mathrm{cm}^{2}$ induces changes in the microstructure of the amorphous Fe-based alloy coating, which manifests itself in a decrease of diffraction intensity as depicted in Figure 12. We postulate that at this elevated neutron dose, radiation-induced defects within the amorphous structure impede and overtake the "fluidity" during loading provided by the ever increasing excess volume or swelling generated by neutron irradiation at this elevated dose. We further postulate that the significant ductility loss observed following irradiation to $2 \times 10^{19} \mathrm{n} / \mathrm{cm}^{2}$ is governed by the role of ${ }^{10} \mathrm{~B}$ and to the contribution of thermal neutrons present in the irradiating mixture. Thermal neu- trons (even in significantly smaller numbers to fast neutrons) induce fission in ${ }^{10} \mathrm{~B}$ into high energy $\alpha$ and lithium particles. These remain in the matrix and with $\alpha$ agglomerating and forming He bubbles promote embrittlement [23-25].

Studies using the monochromatic $67 \mathrm{keV}$ beam at NSLS XPD beamline (transmission mode) and in-situ loading, as in the EDXRD experiments where the amorphous coating was placed under high tensile strains, re-affirmed what EDXRD experimental results have shown thus far and reported in Figure 9, Figure 10, Figure 11 and Figure 12. Specifically, it was shown using a white X-ray beam and EDX$\mathrm{RD}$ techniques that radiation tends to: (a) Enhance amorphization of the coating with increased dose and (b) As the authors deduce/infer from the in-situ application of stress (pure bending with coating 
under high tensile strain), embrittle the amorphous structure. Further evidence of the latter is obtained macroscopically from tensile tests of the combined amorphous Fe-based coating-substrate steel system following irradiation and shown in Figure 13.

In Figure 14 diffraction patterns normalized to

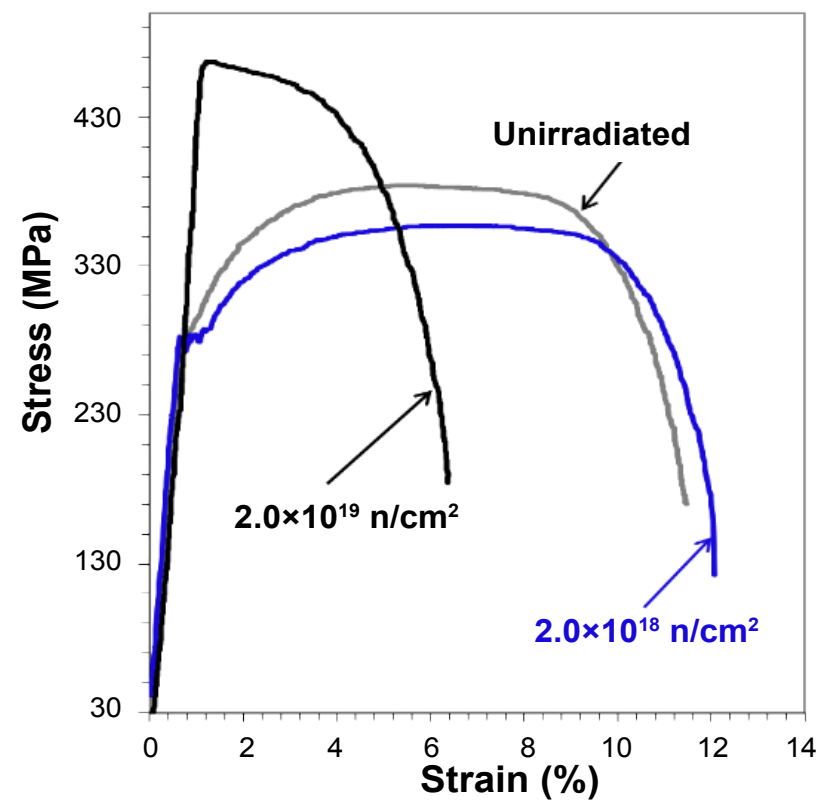

Figure 13: Stress-strain behavior of $240 \mu \mathrm{m}$ amorphous Fe-based alloy coating on bcc steel substrate (1.4 $\mathrm{mm}$ ) under tension, showing the mechanical response of the coating-substrate steel composite system to neutron irradiation where the variation of ductility is clearly seen. Data reproduced from Ref. [16] for comparison.

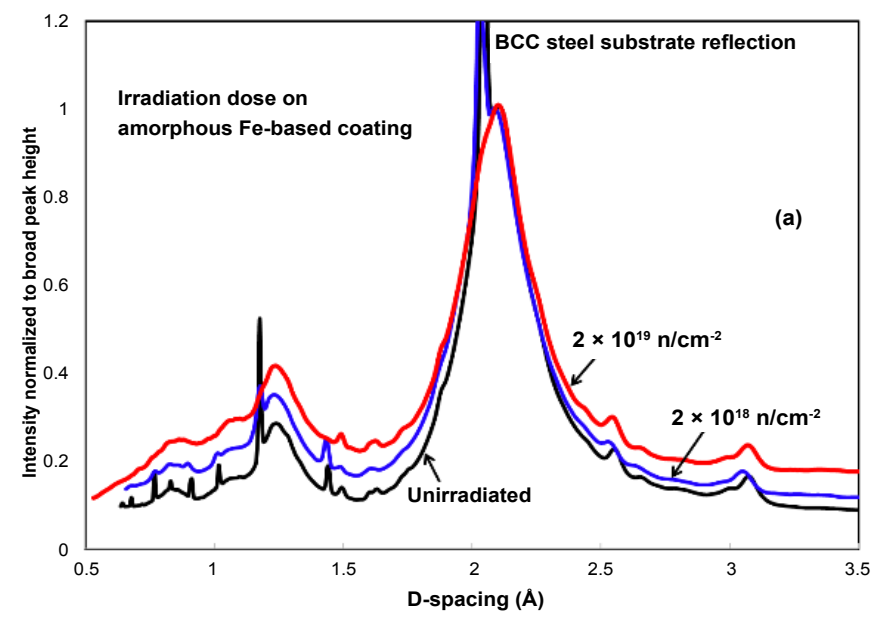

the height of the two broad peaks in the amorphous coating are shown for the control coating (unirradiated) and the two irradiation fluences. Peaks from the substrate BCC steel can also be seen. What Figure 14 clearly shows is that the coating not only remains amorphous but rather has the tendency to become more amorphous (broadening of peak) with increased irradiation owed to the excess free volume generation.

To deduce an understanding of whether the coating, while remaining amorphous, experiences embrittlement, in-situ strain is applied under four point bending putting the coating under high tension (see Figure 4) and repeating the X-ray diffraction experiment. Results shown in Figure 15 are very telling. Specifically, following the lower fluence irradiation $\left(2 \times 10^{18} \mathrm{n} / \mathrm{cm}^{2}\right)$ reflection of the unstrained and the highly strained irradiated coating are similar including the intensity of the broad peak, as if the coating responds in a ductile sense and accommodates the high tension it experiences (Figure 15a). At the higher fluence $\left(2 \times 10^{19} \mathrm{n} / \mathrm{cm}^{2}\right)$ and while the coating is still amorphous (from Figure 14) there is a significant drop in the intensity. The authors attribute that to the only mechanism that could be responsible, that being crack formation in the coating as a result of tensile strain effectively resulting in effective density and thus diffraction reduction.

In an effort to shed more light in the coating embrittlement as a result of high fluence, the micro-

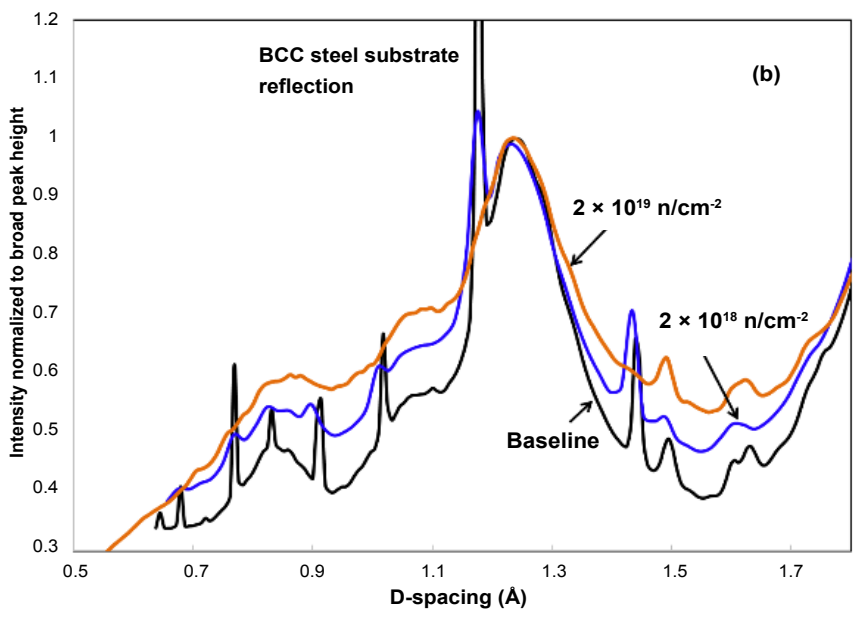

Figure 14: Normalized diffraction patterns from monochromatic $67 \mathrm{keV} \mathrm{X-rays} \mathrm{of} \mathrm{unirradiated} \mathrm{and} \mathrm{irradiated}$ amorphous Fe-based alloy coating: a) Normalization to the height of the dominant broad amorphous peak; and b) Normalization to the second broad peak. Normalization reveals that radiation enhances amorphization (main peak broadening) with increased dose as the baseline (unirradiated) is compared with $2 \times 10^{18} \mathrm{n} / \mathrm{cm}^{2}$ and $2 \times$ $10^{19} \mathrm{n} / \mathrm{cm}^{2}$ states. 

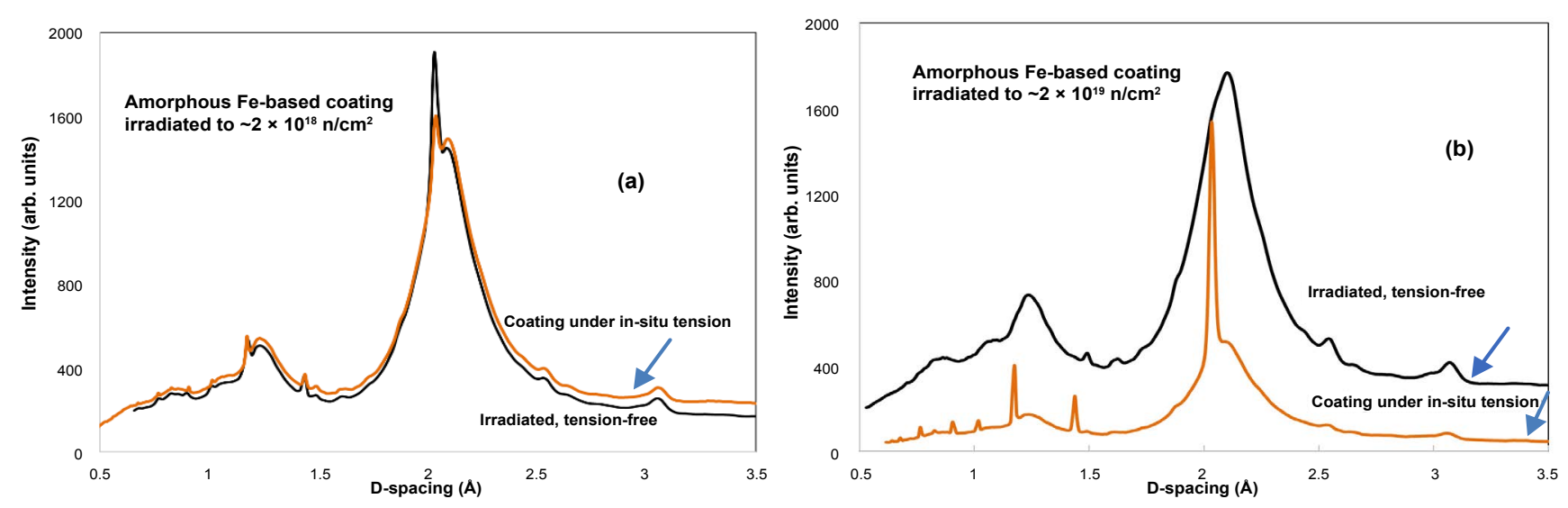

Figure 15: X-ray diffraction patterns of unirradiated and irradiated amorphous Fe-based alloy coating under insitu tensile stress following irradiation to: a) $2 \times 10^{18} \mathrm{n} / \mathrm{cm}^{2}$; and b) $2 \times 10^{19} \mathrm{n} / \mathrm{cm}^{2}$.

scopically observed ductility loss in the composite structure (coating + substrate steel), also reported earlier in Ref. [16] is shown in Figure 13. The data in Figure 13 show that the microscopically observed enhancement of ductility at $2 \times 10^{18} \mathrm{n} / \mathrm{cm}^{2}$ fluence affecting the composite undergoes a significant loss at a fluence of $2 \times 10^{19} \mathrm{n} / \mathrm{cm}^{2}$. It is expected that the substrate steel is primarily responsible for the higher fluence behavior in Figure 13 but still the $240 \mu \mathrm{m}$ coating having itself lost its ductility cannot influence the stress-strain behavior of the composite system as it appears to have done in the lower fluence case. It should be pointed out that the aforementioned comparison should be used with caution since it compares the microscopic response of the coating to the macroscopic response of the coating-substrate composite system.

\section{Summary and Conclusions}

Presented in this study are the effects fast neutrons and mechanical stress (pure bending stress) on phase stability and embrittlement-ductilitization of Fe-based nanostructured amorphous alloys that were initially applied by thermal spraying on bcc steel substrates as a coating. In such a multicomponent system, the liquid iron alloy is splat-quenched and solidified by which the crystallization is suppressed. However, some phase decomposition takes place upon splat-quenching whereby an amorphous Fe-based nanostructured multiphase coating is obtained. The nonequilibrium nature of the process (splat-quenching) and the high concentration of alloying elements results in an amorphous solid which is thermodynamically metastable but kinetically stabilized. The resulting Fe-based coating is essentially a highly al- loyed multiphase amorphous material that imparts great oxidation resistance in comparison to even stainless steels due to its higher alloying content. By utilizing a multitude of advanced experimental methods, we analyzed neutron irradiation-induced crystallization-amorphization phenomenon, irradiation-induced reversal of thermal embrittlement (a.k.a. ductility enhancement) and the behavior of the neutron-irradiated amorphous structure under high stresses. The study revealed the following:

i. The amorphous Fe-based nanostructured coatings show only a weak tendency towards crystallization under fast neutron fluence up to $2 \times$ $10^{19} \mathrm{n} / \mathrm{cm}^{2}$, as evident by the modest narrowing of the characteristic ultra-broad $\mathrm{x}$-ray scattering peak that was observed in the collected spectrum.

ii. Thermally-induced embrittlement is incurred at $350^{\circ} \mathrm{C}$, at which temperature microcracking and increase in the population nanocrystalline precipitates are observed, as evident in the scanning electron micrographs.

iii. Subsequent fast neutron irradiation of thermally embrittled amorphous Fe-based coatings has a healing effect, and confirms results reported in some earlier studies focusing on Fe-based amorphous systems.

iv. The ductility of the amorphous Fe-based coatings that did not undergo thermal embrittlement prior to neutron irradiation, was enhanced upon irradiation. The enhancement was attributed to the generation of excess free volume for neutron doses up to $2 \times 10^{18} \mathrm{n} / \mathrm{cm}^{2}$. 
v. At neutron fluence in excess of $\sim 2 \times 10^{19} \mathrm{n} / \mathrm{cm}^{2}$, radiation-induced defects combine with the effect of thermal neutrons and induce fission in ${ }^{10} \mathrm{~B}$ isotope (present as an alloying element in the amorphous material) which yields high energy $\alpha$ and lithium particles. These particles, which remain in amorphous matrix and agglomerate, form He bubbles that cause embrittlement. Thusly, the ductility of the Fe-based amorphous material is reduced.

vi. The stress-strain measurements on neutron irradiated Fe-based amorphous coatings on steel substrates confirmed the ductility enhancement up to $2 \times 10^{18} \mathrm{n} / \mathrm{cm}^{2}$ followed by an unrecoverable loss at higher neutron fluence, $2 \times 10^{19} \mathrm{n} /$ $\mathrm{cm}^{2}$.

\section{Acknowledgments}

This research was supported by the DOE-NE grant CT-13BN040505. This research used resources of the Center for Functional Nanomaterials, which is a U.S. DOE Office of Science Facility, at Brookhaven National Laboratory under Contract No.DE-SC-0012704. This research used resources at X17-B1 beamline of the National Synchrotron Light Source, a U.S. Department of Energy (DOE) Office of Science User Facility operated for the DOE Office of Science by Brookhaven National Laboratory under Contract No. DE-AC02-98CH10886. This research used resources at XPD beamline of the National Synchrotron Light Source II, a U.S. Department of Energy (DOE) Office of Science User Facility operated for the DOE Office of Science by Brookhaven National Laboratory under Contract No. DESC-0012704.

\section{Conflicts of Interest}

The authors declare no conflict of interest.

\section{References}

1. R Gerling, FP Schimansky, R Wagner (1987) Restoration of the ductility of thermally embrittled amorphous alloys under neutron irradiation. Acta Mettalurgica 35: 1001-1006.

2. R Gerling, FP Schimansky, R Wagner (1988) Ductilization of brittle amorphous alloys and reversible changes of the free volume by thermal treatment. Scripta Mettalurgica 22: 1291-1295.

3. FP Schimansky, R Gerling, R Wagner (1988) Irradiation-induced defects in amorphous $\mathrm{Fe}_{40} \mathrm{Ni}_{40} \mathrm{P}_{20}$. Materials Science and Engineering 97: 173-176.
4. I Škorvánek, R Gerling (1994) Neutron irradiation effects on the structural, magnetic, and mechanical properties of amorphous and nanocrystalline $\mathrm{Fe}_{73}$. ${ }_{5} \mathrm{Cu}_{1} \mathrm{Nb}_{3} \mathrm{Si}_{13.5} \mathrm{~B}_{9}$. IEEE Transactions on magnetics 30: 173-176.

5. A Pundt, G Hampel, J Hesse (1992) Mössbauer effect studies on amorphous and nanocrystalline $\mathrm{Fe}_{73}$. ${ }_{5} \mathrm{Cu}_{1} \mathrm{Nb}_{3} \mathrm{Si}_{13.5} \mathrm{~B}_{9}$. Zeitschrift für Physik B Condensed Matter 87: 65-72.

6. T Nagase, Y Umakoshi, N Sumida (2002) Formation of nanocrystalline structure during electron irradiation induced crystallization in amorphous Fe-Zr-B alloys. Science and Technology of Advanced Materials 3: $119-128$

7. T Nagase, A Nino, Y Umakoshi (2007) Phase stability of amorphous phase against electron irradiation induced crystallization in Fe-based metallic glasses. Materials Transactions 48: 1340-1349.

8. JL Brimhall, LA Charlot, R Wang (1979) Irradiation effects in amorphous and crystalline sputter-deposited Mo-Ni. Scripta Mettallurgica 13: 217-220.

9. J Weis, F Gabris, I Cerven, J Sitek (1984) Amorphous-to-crystalline phase transformation by neutron irradiation of the alloy Fe83B17. Journal of Materials Science Letters 3: 278-282.

10.G Kumar, M Ohnuma, T Furubayashi, K Hono (2008) Thermal embrittlement of Fe-based amorphous ribbons. Journal of Non-Crystalline Solids 354: 882-888.

11.L Kabacoff, S Dallek (2002) Curie temperature and crystallization behavior of amorphous $\mathrm{Fe}_{80} \mathrm{~B}_{15} \mathrm{Si}_{5-\mathrm{x}} \mathrm{Ge}_{x}$. Journal of Non-Crystalline Solids 48: 375-384.

12.Z Li, Z Liu, Y Wang, S Liu, R Jiang, et al. (2015) FeBased amorphous composite coating prepared by plasma Re-melting. Advances in Materials Science and Engineering 2015: 37521.

13.H Ohtani, M Hasebe, K Ishida, T Nishizawa (1988) Calculation of Fe-C-B ternary phase diagram. Trans of Iron \& Steel Inst of Japan 28: 1043-1050.

14.N Simos (2009) Extreme environments of the next generation energy systems and the role of nanocoatings enhancing material performance - sub-micron and nano-structured coatings. Engineering Conferences International Sub-Micron \& Nanostructured Ceramics, Colorado Springs, El Paso.

15.EK Akdoğan (2009) 3D-Quantitative phase analysis \& strain mapping of nanostructured coatings by synchrotron energy dispersive X-ray diffraction: A new approach to materials characterization. Engineering Conferences International Sub-Micron \& Nanostructured Ceramics, Colorado Springs, El Paso. 
16.N Simos, Z Zhong, S Ghose, S Gill, F Camino, et al. (2017) Neutron irradiation and high temperature effects on amorphous Fe-based Nano-coatings on steel - A macroscopic assessment. Journal of Nuclear Materials 489: 164-179.

17.W Guo, J Zhang, Y Wu, S Hong, Y Qin (2015) Fabrication and characterization of Fe-based amorphous coatings prepared by high-velocity spraying. Materials and Design 78: 118-124.

18.WJ Botta, JE Berger, CS Kiminami, V Roche, RP Nogueira, et al. (2014) Corrosion resistance of Febased amorphous alloys. Journal of Alloys and Compounds 586: S105-S110.

19.EK Akdoğan, i Şavklıyıldız, H Biçer, W Paxton, F Toksoy, et al. (2013) Anomalous lattice expansion in yttria stabilized zirconia under simultaneous applied electric and thermal fields: A time-resolved in situ energy dispersive x-ray diffractometry study with an ultrahigh energy synchrotron probe. Journal of Applied Physics 113: 233503.

20.M Croft, V Shukla, EK Akdoğan, N Jisrawi, Z Zhong, et al. (2009) In situ strain profiling of elastoplastic bending in Ti-6Al-4V alloy by synchrotron energy dispersive X-ray diffraction. Journal of Applied Physics 105: 093505.

21.EK Akdoğan (unpublished results).

22.AG Khachaturyan (1983) Theory of structural phase transformations in solids. Dover Publications, Mineola, New York, USA, 198-210.

23.GS Was (2007) Fundamentals of radiation materials science. Springer, New York, USA, 343-423.

24. CHP Lupis (1983) Chemical thermodynamics of materials. Elsevier Science Ltd, 179-183.

25.VS Ramachadran, PJ Sereda (1971) Hedvall effect in cement chemistry. Nature 233: 134-135. 